\title{
Els goigs valencians de sant Vicent Ferrer: cant, lloança i lloança al sant
}

\author{
[Valencian joys to Saint Vicent Ferrer: \\ singing, praise and praise to the saint]
}

\author{
Joan Carles Gomis Corell \\ Conservatori Superior de Música de Castelló (ISEACV) / Universitat de València \\ orcid.org/0000-0002-9777-6213 // joan.c.gomis@uv.es
}

Resum: Sant Vicent Ferrer ha estat des de la seua canonització mereixedor d'una quantitat considerable de goigs. Els primers són les Llaors del gloriós e benaventurat sent Vicent Ferrer, patró de la insigne ciutat de València, composts ben segurament entre 1536 i 1546, cadascuna de les set cobles dels quals exalça un episodi significatiu de la seua vida religiosa, seguint l'esquema dels set goigs marians que donaren origen al gènere. Posteriorment, se li'n compongueren diversos altres, fins i tot uns de satírico-polítics en 1855, en una continuïtat que des del barroc arriba a hores d'ara. El present article estudia totes aquestes composicions, principalment els primers goigs de la primera mitat del segle XVI, centrant-se sobretot en els aspectes musicals: pràctica interpretativa, cantors, instrumentistes i possibles melodies.

PARAules ClaU: goigs, llaors, sant Vicent Ferrer, dansa, contrapunt, cant d'orgue, Miquel Peres

Aвstract: Saint Vicent Ferrer has been from his canonization deserving of a considerable amount of joys. The first are the Glories of the Illustrious and Beatitudinous Saint Vicent Ferrer, Patron Saint of the Insigne City of Valencia, composed very surely between 1536 and 1546, each of the seven verses that exalted a significant episode of his religious life, following the scheme of the seven Marian joys that gave rise to the genre. Later, several others were composed, even satirical-political ones in 1855, in a continuity that comes from the Baroque to the present. The present article studies all these compositions, mainly the first joys of the first half of the 16th century, focusing mainly on the musical aspects: interpretive practice, singers, instrumentalists and possible melodies.

KeYwords: joys, glories, saint Vicent Ferrer, dance, counterpoint, organ singing, Miquel Peres

Recepció: 26/02/2019. Acceptació: 08/03/2019. Publicació: 05/04/2019

REVISTA VALENCIANA DE FILOLOGIA / I I I (20I9) p. 287-322 / ISSN 05 56-70 5X / DOI I0.28939/RVF.V3IO.67 
Entre les pregàries i oracions que assíduament practicava el beat fra Gaspar Bono, José Vicente Ortí y Mayor [1750: 73] ja distingia aquelles que consistien en «[...] cantar algunas alabanzas a los santos (que ordinariamente llamamos gozos) [...]». Efectivament, els goigs, en els termes que els entenen a hores d'ara com a gènere poeticomusical, són himnes religiosos, cant de lloança als personatges i misteris celestials. Per això el títol d'aquesta intervenció trasllada als goigs de sant Vicent Ferrer la famosa definició, considerada fins i tot canònica, que sant Agustí (Enarr. CXLVIII, 17) donà d'himne cristià: «[...] cant, lloança i lloança a Déu. Aleshores, la lloança de Déu en el cant s’anomena himne».

Sense pretendre corregir sant Agustí —els goigs que li canten a Alfara d'Algímia diuen que fou «[...] faro esplendoroso / que, irradiando la verdad, / nunca dio al error reposo [...]»-, ${ }^{1}$ però sí complementar-lo, caldria remarcar una darrera condició o requisit en el cas dels himnes perquè siguen goigs: cant, lloança i lloança al sant —o a la Mare de Déu, a Jesucrist, o qualsevulla personatge celestial一, però amb la forma estròfica de la dansa trobadoresca. Això amb independència de si el títol en diu literalment goigs o els més genèrics llaus, llaors, cobles en alabança o una altra paraula més o menys sinònima. ${ }^{2}$ Afegint-hi aquesta quarta condició, quedaria evidenciada la idiosincràsia dels goigs com a himnes característics dels territoris de llengua catalana, de manera que, fins i tot en alguna ocasió, s'ha considerat aquest gènere com a prova de la internacionalitat d'aquesta llengua (Carbonell 2017: 144-146). No és sols una qüestió d'identitat, sinó també perquè l'ús de la forma estròfica de la dansa determina la tipologia del cant — cant responsorial, propi de la litúrgia cristiana des dels primers moments allà en la Roma de les catacumbes- i, en darrera instància, de la forma musical.

1 Alfara de la Baronia [Alfara d'Algímia], col-lecció particular: [Luis Nadal (?)], Gozos a san Agustín Obispo, patrón de Alfara, [sobreescrit amb bolígraf], San Agustín, [pricipien:] «Para alcanzar santidad [...]», [acaben] «[...] Agustín, sabio glorioso.»; [al marge inferior] Alfara de Algimia y agosto de 1932.

2 Com ja advertí Higini Anglés (1958 III: 637), el nom laude fou molt conegut en el sentit de 'trop'; així, al Prosarium-Troparium Hispanique de la catedral de Girona (F-Pn : Nouv acq Lat 00495), del segle XII, fa servir aquesta paraula per a nomenar els trops del Gloria in excelsis Deo de la missa.

REVISTA VALENCIANA DE FILOLOGIA / II I (20I9) p. 287-322 JOAN CARLES GOMIS CORELL

Els goigs valencians de sant Vicent Ferrer: cant, lloança i lloança al sant / 288 
Dit açò, i considerant que l'estructura estròfica de la dansa començà a aplicar-se, com és ben sabut, a cants en lloança estrictament dels set goigs terrenals de la Mare de Déu d'on, passat el temps, prengué nom el gènere, ${ }^{3}$ hom assumeix —encara que potser caldria revisar aquesta afirmació, però no és ara i ací el moment per a plantejar-la- que els goigs com a gènere poètic i musical en sentit estricte, és a dir, com a composicions laudatòries dedicades a un personatge sagrat fent servir l'estructura estròfica de la dansa trobadoresca, queda definitivament constituit a principi del segle Xvi quan Miquel Ortigues titulà amb dita paraula una composició en lloança, no de la Mare de Déu, sinó d'uns sants, els metges Cosme i Damià, i que es publicaren el 1519 (Amades, Colomines 1946: I, 190). Quedà així associada la paraula goigs amb un gènere poeticomusical de característiques estructurals i valors i significats culturals ben definits. Podria dir-se, fins i tot, que a partir d'aquell moment els goigs es constituïren en una mena d'himnòdia en vulgar del cristianisme. Potser per això - entre altres consideracions-, tantes vegades es repetisca que els goigs són populars: «[...] himnes senzills i devots [... de] lletres antigues i venerables [... cantats amb melodies] d'una gran senzillesa i simplicitat», n'escriu el prevere Francesc Baldelló al pròleg del Cançoner popular religiós de Catalunya (1932: 8, 13). També necessita aquesta consideració una revisió; la farem, sobretot en parlar de la música.

\section{Les 'Llaors del gloriós e benaventurat sent Vicent Ferrer,} patró de la insigne ciutat de València’, primers goigs del sant dominicà

Partint de la cronologia adés acceptada per a l'inici dels goigs com a gènere poeticomusical ja definit, hom pot considerar els primers goigs coneguts

3 No totes les poesies dedicades a lloar els goigs de la Mare de Déu estaven necessàriament escrites en l'estructura de la dansa; així, per exemple, Jaume Roig escrigué totes «les meravelles / virtuts, honors, / premis, lahors / de sola una / mare comuna / e primicera [...]», és a dir, les llaors a la Mare de Déu, en versos de quatre síl·labes, com l'Espill (Roig 1904).

REVISTA VALENCIANA DE FILOLOGIA / I I I (20I9) p. 287-322 JOAN CARLES GOMIS CORELL

Els goigs valencians de sant Vicent Ferrer: cant, lloança i lloança al sant / 289 
de sant Vicent Ferrer — tot i que no es titulen goigs, sinó llaors, però fan servir l'estructura estròfica de la dansa i, per tant, compleixen tots els requisits determinats a l'inici- en són una composició quasi fundacional (fig. 1). No pot precisar-se'n amb exactitud, però, la data de composició. El primer document a hores d'ara conegut que conté aquestes Llaors del gloriós e benaventurat sent Vicent Ferrer... és l'edició del Trellat sumàriament fet de la bulla o confraria del Psaltiri o Roser... del 1546 (s. p. [58-61]). Hi van precedits de les Cobles del Psaltiri o Roser de la intemerada Verge Maria... (s. p. [28-34]), Los goigs de la Verge Maria del Roser (s. p. [37-41]), els Laors de la Verge Maria del Roser (s. p. [41-44]), Les set paraules que Jesús dix en la creu (s. p. [46-49]) i els Laors y cobles de la gloriosa e benaventurada sancta Maria Magdalena, apostolessa (s. p. [50-57]), aquestes dues darreres atribuïdes a Miquel Ortigues. Hi ha, però, una edició anterior del Trellat..., del 1535, la qual, segons la descripció que en fa Ribelles Comín (1929: II, 53-64), no conté les Llaors del... sant Vicent Ferrer..., ni tampoc les dues composicions atribuïdes a Miquel Ortigues. Podría per tant considerar-se que les llaors del sant dominicà podrien haver estat compostes en l'interval dels onze anys que separen ambdues edicions (fig. 1).

Una segona hipòtesi que podria deduir-se'n, per tal com les altres dues composicions que s'afegiren a l'edició del 1546, escrites igualment en la forma de la dansa, s'atribueixen a Miquel Ortigues, seria assignar-li també l'autoria d'aquestes llaors. No semblen, però, composició seua: les obres del notari són vides de sants, quasi en el sentit medieval del gènere, posades en vers. Les Llaors del... sant Vicent... són, seguint el model dels primers goigs marians, una exaltació i meditació piadosa - hauríem de veure-hi la presència de la devotio moderna i de la pietat sentimental franciscana- de set moments essencials — gojosos - de la vida del sant, un per cada cobla, com en aquells, iniciades pel corresponen ordinal: lo primer..., lo segon..., lo tercer fon... Fins i tot el primer goig i el darrer són un trasllat directe dels marians: l'anunciació i concepció del fill de Déu per Maria i la seua assumpció al cel en cos i ànima i, en paral·lel, la concepció de sant Vicent i la representació de l'ascensió de la seua ànima. El text poètic és el següent:

REVISTA VALENCIANA DE FILOLOGIA / I I I (20I9) p. 287-322 JOAN CARLES GOMIS CORELL

Els goigs valencians de sant Vicent Ferrer: cant, lloança i lloança al sant / 290 


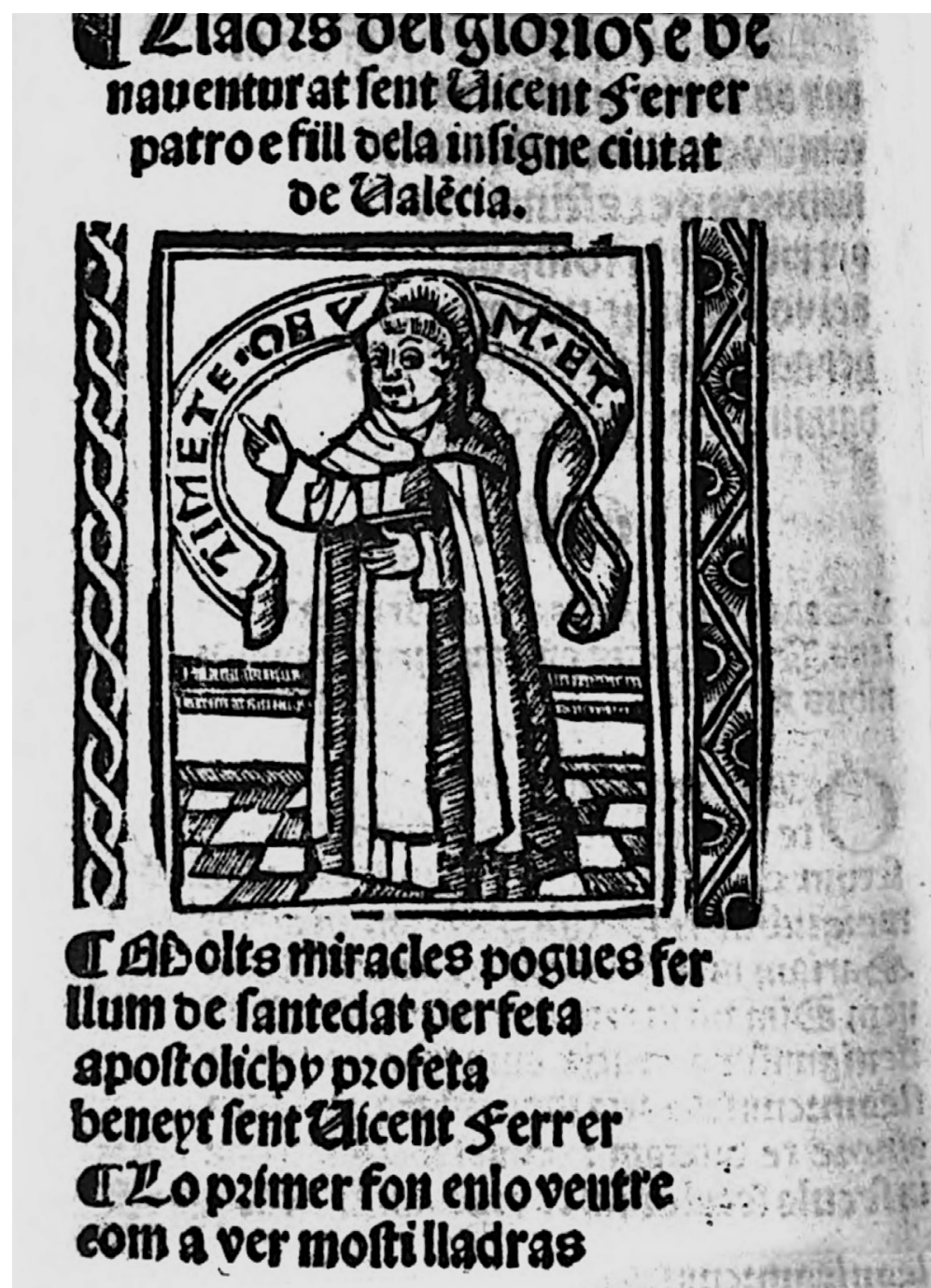

Fig. 1. [Anònim], Llaors del gloriós e benaventurat sent Vicent Ferrer, patró de la insigne ciutat de València, en Trellat sumàriament fet de la bulla o confraria del Psaltiri o Roser..., València, s. i., 1546.

REVISTA VALENCIANA DE FILOLOGIA / I I I (20I9) p. 287-322

JOAN CARLES GOMIS CORELL

Els goigs valencians de sant Vicent Ferrer: cant, lloança i lloança al sant / 29I 
Molts miracles pogués fer, llum de santedat perfeta, apostòlich y profeta, beneyt sent Vicent Ferrer.

Lo primer fon en lo ventre com a ver mostí [per: mastí] lladràs, hon molt clar significàs venir sant en aquest centre, denunciador primer, del juy final trompeta; apostòlich y profeta, beneyt sant Vicent Ferrer.

Lo segon fon en la galta quant vos tocà Jesu Crist, hon molt clarament fon vist que de apòstol res no us falta; predicador fos per a ser la sglésia per vós refeta; apostòlich etc.

Lo tercer que conservada fon vostra virginitat per aquella mà tocat de la Verge consagrada, hon restàs vexel sancer de virginitat perfeta; apostòlich [etc.]

Lo quart fon ésser entesa vostra llengua natural per lo món huniversal y de tots en tot compresa; en tal virtut verdader 
sou estat un clar planeta;

apostòlich etc.

Lo cinqué fon que guaríeu de tot mal a tots malats y de infels y greus defalts a molts pobles convertíeu, mostrant-los ab gran saber la doctrina clara y neta; apostòlich etc.

Lo sisé fon prophecia de les tres naus de forment, que prehicant fes present $\mathrm{y}$ vingueren aquell dia, mostrant Déu per vós voler revellar cosa secreta apostòlich etc.

Lo seté fon que-s mostaren moltes colomes volants, significant los àngels sants que l'ànima us acompanyaren ab goigs, delits y plaer a la pàtria pefeta; apostòlich etc.

Tornada

O, divinal canceller, pregau a Jesús sia feta nostra vida tan eleta com tots havem mester.

Fin.

REVISTA VALENCIANA DE FILOLOGIA / I I I (20I9) p. 287-322 JOAN CARLES GOMIS CORELL

Els goigs valencians de sant Vicent Ferrer: cant, lloança i lloança al sant / 293 
Independentment de qui en fos l'autor, segueixen, llevat de l'episodi del seté goig, l'hagiografia que escrigué Miquel Peres del sant dominicà, publicada el 1510. La primera cobla lloa la concepció del frare dominicà i com se'l sentí lladrar ja al ventre de sa mare, interpretant aquest fet com a anunci de la seua santedat i de la missió anunciadora del juí final (Peres 1510: s. p. [2v.]). La segona refereix el passatge quan Crist, estant malalt fra Vicent, li tocà la galta, confirmació de la seua missió apostòlica; a aquest passatge dedica Peres (1599: s. p. [9v.-10r.]) tot un capítol, si bé no li atorga cap interpretació. La tercera cobla exalça el manteniment de la seua virginitat per «[...] aquella mà tocat / de la Verge consagrada [...]»; Peres (1510: s. p. [2v., 5r. ss.]) insisteix en diversos passatges en la virginitat del sant, i fins i tot relata dos episodis en els quals es posa a prova la resistència, però no l'atribueix a la intercessió directa de la Mare de Déu; el Flos sanctorum (1514: LXXXVIIIv.) només diu quant a això que «[...] vixqué verge e pur». La quarta cobla refereix la missió predicadora del dominicà, significada i evidenciada per la comprensió de la seua «[...] llengua natural / per lo món universal [...]» (Peres 1510: s. p. [p. 3r.]; Flos sanctorum 1514: LXXXIXr.). La cinquena lloa el poder miraculós de guarir malalties (Peres 1510: s. p. [2v., 3r., 5r., 8r.-9v., ss.]) i de convertir heretges $\mathrm{i}$ infidels - «[...] .xxv. mília d'ells a la lum de veritat reduy", s'especifica al Flos sacntorum (1514: LXXXIXr.). La sisena refereix la profecia dels vaixells que, carregats de forment, arribarien al port de Barcelona perquè «[...] estimats jermans $[\ldots]$ vostra fam y fretura serà complidament socorreguda» (Peres 1510: s. p. [p. 8r.-v.]). Finalment, la setena cobla exalça l'ascensió de l'ànima de fra Vicent acompanyada d'àngels, significats per «[...] moltes colomes volant [...]», únic episodi que no refereix Miquel Peres, ni tampoc mossén Catalunya al Flos sanctorum i que posteriorment recollirà Vicente Justiniano Antich (1575: 321).

Per a explicar la producció i l'estampació d'aquest tipus de literatura, s'esgrimeixen com a causes el vigor i potencial de la ciutat de València en aquell temps, tant econòmic com demogràfic — la Llotja de mercaders, símbol arquitectònic per excel-lència d'aquella conjuntura estava construint-se simultàniament- i el conreu de temes religiosos vinculats a les classes ciutadanes per

REVISTA VALENCIANA DE FILOLOGIA / II I (20I9) p. 287-322 JOAN CARLES GOMIS CORELL

Els goigs valencians de sant Vicent Ferrer: cant, lloança i lloança al sant / 294 
reacció a la poesia cortesana en castellà. Poesia burgesa, urbana, mercantil fins i tot, enfront de la poesia aristocràtica. No ha de desestimar-se, però, una qüestió essencial: la finalitat d'aquesta poesia — bé goigs, bé gèneres semblants- va ser induir a la reflexió piadosa i incitar a la pietat — «para exercitar a las gentes a más devoción", deia el títol d'unes cobles a sant Roc estampades a Toledo en la segona dècada d'aquell mateix segle XVI- i, alhora, difondre i afermar creences entre els fidels, sobretot entre aquells que no podien accedir a la lectura de les hagiografies i llibres de pietat (Gomis Corell 2015, 2018). ${ }^{4}$ Miquel Peres (1510: 17r.) posa en boca de sant Vicent Ferrer el següent consell, que donà als seus seguidors en sentir que li arribava l'hora del traspàs:

No ligau libres de fengides poesies, de inútils històries ni de combats ni batalles, mas libres de la Sagrada Scriptura on veritat se troba; y libres que lo vostre fret y gelat cor a fervent devoció ençeng[u]en y de mals pensaments vos aparten; legiu los sagrats Evangelis [...] y los qui legir no sabreu $[\ldots]$ legiu en lo libre de la vostra memòria $[\ldots]$.

Per això l'ús del vulgar i, sobretot, el fet de cantar-los, ja que en tindre l'estructura de la dansa, el cant repetit del respòs després de cada cobla, obri la possibilitat a la participació dels qui escolten en moments puntuals del cant, refermant allò de «legiu en lo libre de la vostra memòria». ${ }^{5}$ El mateix origen, medi i valor tingué la lauda italiana, derivada també de l'expandiment de la

4 Coplas hechas por un religioso de la orden de san Agustín del bienaventurado sant Roch, conformes a su historia, para exercitar a las gentes a más devoción.... [Toledo]: [por Juan de Villaquirán], [ca. 1513-1520], Biblioteca Nacional de España, VE/109/32; cf. Carvajal [2003: 102-106]. Aquestes composicions encara incitaven més a pietat perquè les estampacions anaven encapçalades per la imatge xilogràfica del sant o del corresponent personatge celestial al qual estaven dedicades. Amb això assolien el valor d'estampes devocionals que situaven en l'àmbit personal i en l'espai domèstic les imatges sagrades que havien de venerar-se.

5 La dansa, en no mesclar refranh i cobles, determina clarament el moment de cant a solo i el del cor —o participació dels fidels-. En la dansa original, però, els dos versos del respòs, com que només repetien la rima del refranh, venien marcats sobretot per la melodia. Potser per això, per a facilitar la participació dels devots en el cant —serien els equivalents al cor-, la dansa acabà simplificant-se i prengué per respòs els dos darrers versos del refranh, completant amb ells cadascuna de les cobles.

REVISTA VALENCIANA DE FILOLOGIA / I I I (20I9) p. 287-322

JOAN CARLES GOMIS CORELL

Els goigs valencians de sant Vicent Ferrer: cant, lloança i lloança al sant / 295 
poesia trobadoresca per aquells territoris, un gènere que possiblement està més relacionat amb els goigs valencians del que a hores d'ara considerem, aspecte sobre el qual insistirem en parlar-ne de la música.

Els goigs, un gènere popular? En el segle XVI, només quant a ús, intenció i finalitat, no pas quant a composició ni interpretació. Josep Palàcios (1977: III, XIII) ja plantejà que aquests poemes religiosos de principi dels cinc-cents havien de considerar-se populars només "[...] des de l'angle del consum [...] perquè estaven enfocats cap a aquesta destinació: per a ser consumits "popularment", això és, pel segment social majoritari». Possiblement ni això, com veurem, o potser caldria valorar la possibilitat de qualificar-los de poesia populista amb el valor que Antoni Ferrando (1987: 55-74) assignà a certa literatura del segle Xviı valencià.

\section{Música i cant}

Aquests primers goigs de sant Vicent Ferrer, també la major part dels que es compongueren en el segle XVI, es cantaren, no ha d'haver-hi dubte. Ho indiquen alguns al títol —Los goigs de la gloriosa Mare de Deu de la Concepció, los quals se cantan en la Encarnació- ${ }^{6}$ o ho especifica la mateixa composició — "Vostres goigs ab gran plaer / cantarem, Senyora mia [...]», comencen Los goigs de la Verge Maria del Roser (Trellat 1546: s. p. [38])—, però sobretot no deixa dubte sobre aquest aspecte la constatació que fan les constitucions sinodals del 1594 de l'arquebisbe Juan de Ribera (1594: s. p. [1-2]):

[...] les imatges de les confraries [...] a les quals més afecte té el poble, en la nostra ciutat es tenen, això no obstant, amb menys decor que en unes altres, per tal com es col-loquen en les cases dels menestrals, en llurs tallers, sabateries [...]. Algunes vegades fins i tot les duen a bodegues i, de

6 [Vilaespinosa, P.], Los goigs de la gloriosa Mare de Deu de la Concepció, los quals se cantan en la Encarnació, [s. 1l., s. n., s. a.: València, 1501?], Universitat de València, BH CF/4 (16); a més d'aquesta edició, Genovés y Olmos (1911: I, 93-94) en cataloga una altra que detalla la data d'impressió, 1525, i l'autoria de Pere Vilaspinosa.

REVISTA VALENCIANA DE FILOLOGIA / I I I (20I9) p. 287-322 JOAN CARLES GOMIS CORELL

Els goigs valencians de sant Vicent Ferrer: cant, lloança i lloança al sant / 296 
manera habitual, a habitacions on de nit es giten a dormir i s'hi fan altres coses semblants [...]. Per això, en quedar les esglésies parroquials en una soledat excessiva, dissabtes al vespre s'acudeix de tot el veïnat a aquelles habitacions profanes, i allí cantors i citaristes canten la Salve regina, goigs $\mathrm{i}$ altres pregàries, com als edificis sagrats.

Si més no, sembla quedar clar alguns dels moments, llocs i situacions en els quals es cantaven goigs: en les festes de confraries i gremis, en les festes de barri i de carrer. Els goigs hagueren de ser també, per consegüent, una mena de senyal d'identitat de cada corporació, gremi o confraria, un himne propi per al seu sant o personatge celestial particular. Ara bé, no ha de pensar-se en un cant comunal com en l'actualitat, amb molts fidels, full dels goigs en mà, cantant-los amb una senzilla melodia que repeteixen mecànicament i literal una vegada i una altra fins acabar la composició. Els cantaven "cantors i citaristes», és a dir, músics professionals. Veus i instruments de corda. Unes sonoritats que poc a veure - $\mathrm{O}$ a sentir - tenen amb les que actualment s'escolten quan es canten goigs.

\section{Els músics: cantors i instrumentistes}

Que les Constitucions sinodals del 1594 especifiquen la participació de cantors i citaristes en aquelles celebracions festivoreligioses dels dissabtes de vesprada a la ciutat de València, ha d'entendre's com a referència inequívoca a músics professionals lliures, espècie de capelles musicals que no depenien de cap institució i que es llogaven per cantar i tocar en les diverses festes que se celebraven a la ciutat o als llocs dels voltants. El baró d'Alcahalí (1903: 134), a partir del Manual de Consells, constata que a la ciutat de València hi havia en el segle Xvi músics que

[...] no tenían carácter alguno oficial, ni más salario que el convenido cada vez que se les ajustaba para funcionar en algún acto público; se agenciaban como podían para explotar su habilidad, contratándose con todo aquel que deseaba utilizarlos. Esto produjo en varias ocasiones verdaderos

REVISTA VALENCIANA DE FILOLOGIA / I I I (20I9) p. 287-322 JOAN CARLES GOMIS CORELL

Els goigs valencians de sant Vicent Ferrer: cant, lloança i lloança al sant / 297 
conflictos a la ciudad, que al ir a contratarlos se encontró con que tenían ya compromiso previo contraído. Para obviar tales inconvenientes, y considerando los Jurados más decoroso el tener perennemente a su servicio una sección de ministriles escogidos que no pudiera utilizar nadie más que la Ciudad y que tuvieran señalado un sueldo fijo, propuso en Consejo de 20 de septiembre de 1524 el magnífic en Luis Granulles que «donat los Ministrils molta honor a la ciutat es menester conduir als cuatre que y•á y pagarlos de alguna part puix la Ciutat no pague cosa alguna».

L'activitat musical en una ciutat com la de València, cap i casal del regne, era molt intensa, impossible de satisfer només amb els músics de les capelles eclesiàstiques o de la noblesa. La contractació de músics professional lliures era necessària. Carreres Zacarés (1926: 363-370) constata que amb motiu de la boda del rei Felip II d'Aragó i III de Castella a la ciutat de València el 1599, a més de la participació dels ministrers de la ciutat — contractats pels jurats, com acaben de dir, des del 1524_, s'efectuaren pagaments a diversos músics més per llurs actuacions: per tocar en l'entrada del rei, seixanta reals a Joan Tudó i vuitanta a Andreu Perelló; cent dotze a Jeroni Olzina i a la seua cobla per tocar en l'entrada de la reina i en un sarau; hi intervingueren també Dimas Aguilar i altres músics, els quals cobraren setanta reals; igualment participà en aquelles festes reials Jeroni Ortí, dolçainer, i la seua cobla, i cobraren quatre lliures i deu sous per quatre nits de faena. ${ }^{7}$ Tanta demanda de músics hi havia, sobretot en celebracions especialment senyalades, que durant les festes de beatificació de l'arquebisbe Tomás de Villanueva, a més dels ministrers «[...] que hay en esta ciudad [de València] muchos, por ser grande i populosa [...] baxaron para este caso, sin duda, a la ciudad todos los del reyno» (Martínez de la Vega 1620: 49).

També es documenten aquests músics professionals lliures en altres llocs de la corona catalanoaragonesa. A la ciutat de Saragossa, en el darrer quart d'aquell segle XVI, actuava en aquestes funcions festives el músic Jerónimo

7 La descripció d'aquestes entrades i posteriors celebracions foren recollides i narrades per Juan Esquerdo (1599).

REVISTA VALENCIANA DE FILOLOGIA / I I I (20I9) p. 287-322 JOAN CARLES GOMIS CORELL

Els goigs valencians de sant Vicent Ferrer: cant, lloança i lloança al sant / 298 
Muniesa, «[...] un singular maestro de canto, quien con los cantores a los que enseñaba y con los que firmaba contrato, formaba una capilla de música y se alquilaba por la ciudad en cada fiesta por el interés y ganancia que de ello sacaba» (Calahorra 1977: 79). També se'n constaten a Castella (Berjano Pellicer 2015).

Quant als instruments, les constitucions sinodals són molt poc explícites. Si considerem que als instrumentistes de vent se'ls anomenava generalment ministrers — de fet, la capella de ministrers de la catedral que, sota la direcció de Lope del Castillo, es fundà el 1560, estava constituïda per quatre xeremies, sacabutx, corneta, flauta, cromorn i trombó (López Calo 1983: 43-44)—, el terme citaristes al-ludiria a instruments de corda en general, segurament violes d'arc, documentades en la interpretació de música religiosa quan les festes celebrades a la ciutat de València per l'arribada de la relíquia de sant Vicent Ferrer el 1600 — «había un juengo de vihuelas de arco con que se tañían varios motetes, ensalades y villancicos con gran suavidad y destreza» (Francisco Tárrega 1600: 20-22) - i amb motiu de la canonització de sant Ramon de Penyafort (Gómez 1602: 12). En el cas del susdit Jerónimo Muniesa, però, era «[...] un bajón, que siempre sonaba junto a sus cantores [...]» (Calahorra 1977: 80). Ara bé, com també diu Francisco Tárrega (1600: 20-22), «de toda esta música [de les festes de la relíquia de sant Vicent] se hazían mil manera de conciertos y choros, quando juntando las bozes con las vihuelas, quando concertando el árgano con ella, y los menestriles, y quando mezclándose todos [...]».

\section{La melodia}

No coneixem documentalment —és a dir, escrita sobre pauta musical-a hores d'ara cap melodia de goigs del segle xvi. Això no vol dir que no existiren o que hagen estat destruïdes. ${ }^{8}$ La impremta estampà i difongué els textos

8 Algunes, però, sí; la melodia catalana més antiga coneguda per a cantar els Goigs del la Verge del Roser, escrita en notació quadrada, estava «en un pergamí [retallat en part] que servia de carpeta a uns Papers fahents per la fermansa que féu Jaume Cristòfol de Guimerà a Miquel Àngel Salavert per la bulla

REVISTA VALENCIANA DE FILOLOGIA / I I I (20I9) p. 287-322 JOAN CARLES GOMIS CORELL

Els goigs valencians de sant Vicent Ferrer: cant, lloança i lloança al sant / 299 
— primer en opuscles de deu o dotze fulles; posteriorment, en fulls volanders-, però no feu el mateix amb les melodies. En primer lloc perquè, en el inicis de la impremta, era tècnicament difícil i car estampar la pauta musical; en segon lloc, perquè les composicions en llengua vulgar feien servir habitualment melodies manllevades, bé del repertori eclesiàstic, bé del profà. ${ }^{9} \mathrm{~A}$ més, ha de tenir-se en compte que en aquelles dates la música no sempre s'escrivia ni, en el cas d'escriure's, s'escrivia completa. Tenia un gran component d'improvisació. Sobre una melodia coneguda, els cantors i instrumentistes, posseïdors de gran perícia musical tant per la pràctica continuada però també per l'aprenentatge previ dels diversos procediments d'interpretació, improvisaven —seguint unes regles, és clar - una altra veu per dalt, o per baix, o per dalt i per baix simultàniament. És a dir, feien contrapunts, els quals no es traslladaven a la pauta musical. «Fer contrapunts» era estrictament una pràctica interpretativa. La composició era una tasca distinta, pròpia del mestre de capella, i consistia - ho especifica Bermudo (1555: V, XVI, CXXVIIIr.) - en un procés reflexiu d'estructuració i coordinació de totes les veus des de l'inici, amb especial cura. El resultat s'anomenava cant d'orgue, i s'escrivia, amb més o menys detall. ${ }^{10}$

de Tarragona, trienni 1596. -n ${ }^{\circ} 116$ [...]» (Briz et. al. 1877: V, 37; Baldelló, 1939: 232-233). Molts pergamins amb música escrita degueren reaprofitar-se per a uns altres menesters; l'arxiu musical de la catedral de València, per exemple, no conserva música anterior al segle XIV.

9 El notari Joan de Campos, o algun dels seus escrivans, anotà al primer foli d'un notal del 1464 (Arxiu del Regne de València, Protocols, Notal de Joan de Campos, 2528, f. 1r.) una composició en la forma de la dansa dedicada als set goigs de la Mare de Déu (no du títol, però ben bé hom pot titular-la Goigs de Nostra Senyora) que, sens dubte, hagué de cantar el notari, perquè així ho diu el tercer vers de la composició: «[...] cantaré ab gran amor / vostres goigs, Senyora mia [...]»; no hi anotaren, però, la melodia; en primer lloc, perquè el llenguatge musical i les seues grafies són tan específiques que requereixen necessàriament d'una formació prèvia i, en segon lloc, perquè quasi amb total seguretat aquells goigs els entonaren amb una melodia manllevada i, per tant, sabuda de memòria.

10 Es conserven alguns goigs, molt pocs realment, compost a cant d'orgue: el Madrigal I. Goigs de Nostra Dona, de Joan Brudieu, del 1585 (Casas 2005), els que compongué entre el 1608 I el 1610 Joan Baptista Comes per a les quatre invocacions de la Capella Major del Col-legi de Corpus Christi de la ciutat de València (Báguena Soler 1955; Gomis Corell 1999: 171-195), i la publicació el 1702 dels goigs de sant Bru, amb polifònica de Jerónimo de la Torre (Ballús i Casòliva, Ezquerdo Estevan 2013). També tenim el testimoni documental dels Goigs de sant Ramon de Penyafort amb motiu de la festa de la seua canonització el 1601: els frares del convent de Santa Caterina de Barcelona —on se'n venerava la relíquia-, és a dir, la capella musical, els interpretaren a "canto de órgano [...] con mucha música», (Jaume Rebullosa 1601: 21, 22, 36).

REVISTA VALENCIANA DE FILOLOGIA / I I I (20I9) p. 287-322

JOAN CARLES GOMIS CORELL

Els goigs valencians de sant Vicent Ferrer: cant, lloança i lloança al sant / 300 
Coneixent les pràctiques musicals d'aquell moment $\mathrm{i}$ sabent que eren cantors i citaristes professionals qui els interpretaven, no pot haver-hi dubte que els goigs degueren cantar-se habitualment amb contrapunt improvisat - «contrapunto suelto» l'anomenarà després Tosca en el Compendio mathemático (1727 [1709]: II, 474)—. Per tant, en cada interpretació el resultat sonor era distint. Les composicions s'ampliaven i es modificaven fins a l'extrem que, durant les festes de la canonització de sant Tomàs de Villanueva, Ortí (1659: 252) s'admirà de la música que s'interpretà perquè «[...] sin embargo de haverla continuado todos los días, cada vez suspendía tanto como si saliera de nuevo, de más de que siempre se le ivan añadiendo varias circunstancias que la realçavan, de suerte que siempre se experimentavan muchas novedades [...]».

Les característiques de les composicions de goigs a cant d'orgue que a hores d'ara coneixem — Brudieu, Comes i de la Torre- i considerant l'afirmació de Cerone (1613: 565-594) que en les capelles musicals el contrapunt comú era el més usat, possibiliten pensar que els goigs degueren cantar-se habitualment a contrapunt pla o disminuit a dues veus o a contrapunt senzill a tres veus sense imitacions i, els compostos a cant d'orgue, a contrapunt a una veu sobre dit cant. ${ }^{11}$ Altres procediments més complexos de fer contrapunts només els practicaven les capelles musicals especialment destres, com ara la de la catedral, «[...] que es de las famosas y regalada que hay en Iglesia de la christiandad, sin agravio de las más principales» (Gómez 1602: 13). ${ }^{12}$

11 Recialla i ensems testimoni d'aquella pràctica contrapuntística improvisada potser siga que per a cantar goigs perduren en la tradició oral uns pocs tipus melòdics de polifonia molt senzilla i elemental, fossilitzats per les successives simplificacions per adequar-los a les possibilitats d'intèrprets sense instrucció musical. Alguns es limiten a fer una veu paral·lela a distància de tercera, bé superior, bé inferior, sobre la melodia; uns altres condueixen en algun moment l'altra veu per moviment oblic i fins i tot contrari. No s'ha fet encara un recull ni sistematització completa de tots els tipus melòdics que en la tradició oral valenciana perviuen per cantar goigs, però alguns han estat transcrits per Salvador Seguí (1973: 31-34, 37, 39-43; 1980: 848, 852, 857, 859, 861, 864, 866-867, 869, 870-871,876-878; 1990: 464, 465, 473, $475,480,485,486-487,488,489,494,495,496,500,501,504-505,507-511) ;$ també s'ha fet l'anàlisi detallada d'alguna d'aquestes melodies (Gomis Corell 1993: 41-45, 49-52; 1996: 485-486, 495).

12 Bermudo (1555:V, XVI, CXXVIIIr., XVIII [per XVII], f. CXXIXr.) posa com a models d'aquestes capelles especialment destres en el contrapunt improvisat la de l'arquebisbe de Toledo Fonseca i la de la Capilla Real de Granada; hi explica, a més, els diversos tipus de contrapunt.

REVISTA VALENCIANA DE FILOLOGIA / I I I (20I9) p. 287-322

JOAN CARLES GOMIS CORELL

Els goigs valencians de sant Vicent Ferrer: cant, lloança i lloança al sant / $30 \mathrm{I}$ 
Claudio Gallico (1986 [1978]: 25-26) considera que l'escassa presència de compositors pròpiament italians en les fonts escrites de l'Ars nova en la segona mitat del Quattrocento és deu a la «[...] vocación humanística de los músicos italianos para cantar de memoria en su lengua materna, solos o acompañados de un instrumento». Tot seguit, en parlar dels procediments d'aquells músics, afig:

Se sabe que improvisaban cantando poesía lírica italiana y tocando [...] el arte de aquellos músicos tenía algo de variación, elaboración y paráfrasis. Pertenecía en cierto modo a una cultura nacional, ciudadana, cortesana y burguesa, sólo aparentemente popular, porque no estaba escrita y estaba muy divulgada. No era espontánea, pero sí estudiada y profesional.

Aquestes mateixes característiques són aplicables als goigs, si més no als del segle xvi, encara que a hores d'ara no coneixem cap testimoni que puga indicar, ni tan sols insinuar, quina fou la melodia amb la qual es cantaren aquestes llaors de sant Vicent. ${ }^{13}$ Tot i això, si anteriorment ja havíem assenyalat el paral-lelisme d'intenció entre aquestes i la lauda italiana, també cal establir-lo, novament seguint Gallico (1986 [1978]: 29), en els aspectes musicals:

La lauda, lírica italiana de inspiración religiosa, no litúrgica, se entona a varias voces en el estilo que sigue la línea nacional. Son simples poesías estróficas o en forma de himno [...]. Se entonan con una melodía muy clara, concisa: puede ser un canto nuevo; pero también un canto tradicional devoto, o bien un canto profano y conocido sujeto a la simulación espiritual de cambiar las palabras. Este último era un procedimiento común y facilitaba la comodidad del repertorio, la rápida memorización, la facilidad en la ejecución, la difusión popular del texto. Así, en las fuentes más antiguas de laudas literarias se lee la recomendación «cántese del siguiente modo» seguida del íncipit de una canción mundana $[\ldots]$

13 Tot i saber que era habitual manllevar melodies, resulta arriscat plantejar ara i ací una hipotètica reconstrucció sonora de les llaors de sant Vicent Ferrer a partir d'algunes melodies que encara conserva la tradició oral valenciana, ja que constituiria un altre estudi que ultrapassa els límits de la present intervenció.

REVISTA VALENCIANA DE FILOLOGIA / II I (20I9) p. 287-322

JOAN CARLES GOMIS CORELL

Els goigs valencians de sant Vicent Ferrer: cant, lloança i lloança al sant / 302 
No són tan nombrosos sobre aquest aspecte els testimonis documentals valencians, però hi ha la Cançó de la beneita Verge Maria, Mare de Déu, a cantar al so "Si bé em sóc malmaridada, jo me n’he..." (Fuster 1827: I, 293; Villanueva 1902: II, 197-198) que acompleix tots els paràmetres que Gallico defineix per a la lauda. En aquest sentit, cal remarcar que, efectivament, en el segle XVI, amb el nomenament com a virreis de Germana de Foix i Ferran d'Aragó, duc de Calàbria, s'establí per primera vegada a la ciutat de València una cort permanent, culta i refinada, amb formes i maneres semblants a les de les corts urbanes italianes, i les influències van ser evidents. Tot i que el conreu de la poesia religiosa en vulgar començà a València abans, el model italià, si més no en l'àmbit musical, degué deixar-se sentir entre els músics nadius. L'estat en el qual està actualment la investigació no permet afirmar que els goigs i altres composicions religioses no litúrgiques semblants siguen els gèneres específics de la música renaixentista valenciana, però sí que pot dir-se que aquells "cantors i citaristes» $\mathrm{i}$ llur repertori, tot i l'escassesa dels testimonis que ens han arribat, foren el continuadors d'una pràctica d'interpretació musical professional valenciana en paral-lel a la música estrictament litúrgica. Cal, per tant, situar els goigs, com ha fet la musicologia italiana amb la lauda si més no des de la dècada dels anys setanta del segle passat, en l'àmbit artístic i patrimonial que els pertoca i diferenciar-los d'aquella posterior popularització - la qual no pot negar-se, però- massa idealitzada per folkloristes i etnomusicòlegs.

\section{5. Ús i pervivència dels Llaors del gloriós e benaventurat sent Vicent Ferrer}

No és coneix actualment cap estampació d'aquestes llaors en els tan habituals, sobretot a partir del segle xvir, fulls volanders. Sabem, però, que es cantaren. El 7 d'abril del 1600 entrà en la ciutat de València — ja s'ha referit anteriorment- una relíquia de sant Vicent Ferrer arribada des de Vannes, la qual, finalment, per determinació del Consell de la Ciutat, va estar dipositada per a veneració pública a la casa del sant. Pere Joan Porcar (2012: I, 105) escriu al seu dietari que rebia «[...] molta freqüentació de gent. Y los capellans de Sent

REVISTA VALENCIANA DE FILOLOGIA / I I I (20I9) p. 287-322 JOAN CARLES GOMIS CORELL

Els goigs valencians de sant Vicent Ferrer: cant, lloança i lloança al sant / 303 
Steve assistien cantant molts goigs». La notícia és breu i poc explícita, però a més de constatar el cant dels goigs, potser és més significatiu el fet que especifica qui els cantaven: els capellans, i no els fidels qui hi acudien a venerar-la. ${ }^{14}$ A mitjan segle XVII continuarien cantant-se, per tal com Vicente Calbo, oficial de les secretaries de Marc Antoni Ortí (secretari de la ciutat de València i, entre altres càrrecs, regent del Llibre de Memòries de la Ciutat), empra els dos versos del respòs per tal de cloure les Quintilles que escriu amb motiu de la publicació del llibre del segon centenar de la canonització del sant (Ortí 1656: s. p. [14]):

[...]

Vós, o patró verdader, lo treball que l'inquieta, sou lo que podeu desfer, apostòlic i profeta, beneït sanct Vicent Ferrer.

Hi ha també indicis per a considerar que a mitjan segle XviII encara es cantaven o, si més no, mantenien certa difusió entre les persones lletrades. Ortí y Mayor (1750: 42), en la hagiografia de fra Gaspar Bono, fa cantar al frare franciscà els goigs de sant Vicent Ferrer «[...] en nuestro materno idioma, por excitarle más a devoción [...]». A més, tot i haver dit anteriorment que no es coneix a hores d'ara cap full volander amb aquestes llaors, sembla que pogueren haver sigut estampades. Novament és Ortí y Mayor (1790: 90) el qui, en descriure la cel·la de fra Gaspar, diu que «en las paredes no avía guadamasiles, lienzos ni otras pinturas que estampicas de papel muy ordinarias de Nuestra

14 Un altre indici que referma que el cant dels goigs era tasca de músics professionals és que eren els fidels els qui en demanaven aquell cant. Juan Ten, en comprovar que el seu fill Baltasar, de tres anys, havia mort «[...] se encaminó a la iglesia de el Socorro y, postrado delante de la sepultura de nuestro santo [Tomàs de Villanueva], dispuso le cantassen unos gozos, y le rogó alcanzasse para su hijo la vida [...]»; en març de 1602, Isabel Peris, esposa del llaurador Joan Peris, per haver superat un part molt perillós gràcies, suposadament, a l'ajuda miraculosa de l'aleshores encara beat Tomàs de Villanueva, anà a escoltar missa «[...] al convento de el Socorro, y dexó limosna para este safrificio y para unos gozos» (Ortí y Mayor 1731: 286, 301). Cap al·lusió, però, a com sonaren aquells goigs. La mateixa constatació, a la ciutat de Barcelona amb els Goigs de sant Ramon de Penyafort, fa Rebullosa (1601: 39, 40, 55, 58, 89).

REVISTA VALENCIANA DE FILOLOGIA / I I I (20I9) p. 287-322

JOAN CARLES GOMIS CORELL

Els goigs valencians de sant Vicent Ferrer: cant, lloança i lloança al sant / 304 
Señora, de san Joseph, de santa Ana, de san Vicente Ferrer con los gozos al santo en lengua valenciana [...]». Això no obstant, Navarro Cabanes (Diario de Valencia 11-IV-1915) tampoc no va veure cap full volander d'aquestes lloes, i en conegué el text a través d'un full manuscrit que tenia l'aleshores director del Diario de Valencia, Juan Luis Martín y Mengod, unit a una hagiografia del sant publicada a mitjan segle XviII. Aquest text és el que després publicà Almarche (1917: 189-190).

\section{Goigs de sant Vicent d'època barroca}

Com ja s'ha dit, «divendres, a 7 de abril 1600, a les tres hores de la vesprada entrà en Valèntia una relíquia del gloriós patró nostre [...] Y feren gran festa de campanes y músices y la depositaren a la sala de Valèntia» (Porcar 2012: 103). El dia 17 d'aquell mateix més la portaren en processó a la seu, on va estar rebuda «[...] dando la capilla a choros / mil versos y chançonetas [...]» (Recebimiento 1600: [5v.]). L'any següent, l'arquebisbe Ribera n'aconseguia una altra —una canella - per al seu Col-legi de Corpus Christi. Per a celebrar-ho, Joan Baptista Comes compongué a cant d'orgue i solo d'infant uns goigs a sant Vicent Ferrer amb lletra nova, en castellà, escrita segons tradició d'aquest col·legi pel mateix Juan de Ribera (Comes, 1955: 4-5). Tenen la relíquia com a eix argumental, exalçant el seu poder guaridor, repetit insistentment tant que respòs després de cada cobla: «[...] que Cristo sana a Vicente / y él sana con su canilla». Pel tipus de composició musical, foren goigs que només degueren cantar-se al Col-legi de Corpus Christi per la capella musical de la institució. Tot i això, a mitjan segle XIX i després en els anys trenta del segle XIx, s'estamparen en fulls volanders (fig. 2). ${ }^{15}$

15 [Juan de Ribera], Gozos al glorioso san Vicente Ferrer, según se cantan en la Capilla del Real Colegio de Corpus Christi de Valencia, en donde se venera la preciosa reliquia de la canilla, y un dedo del mismo santo, s. 1l. [València], s. i. [Agustín Laborda], s. a. [1770 ca.], Universitat de València, BH Var. 010(073); [- ], Gozos al glorioso san Vicente Ferrer, según se cantan en la capilla del Real Colegio de Corpus Christi de Valencia, en donde se venera la preciosa reliquia de la canilla, y un dedo del mismo santo, s. 1l. [València], Ferrer de Orga, s. a. [1830 ca.].

REVISTA VALENCIANA DE FILOLOGIA / I I I (20I9) p. 287-322 JOAN CARLES GOMIS CORELL

Els goigs valencians de sant Vicent Ferrer: cant, lloança i lloança al sant / 305 


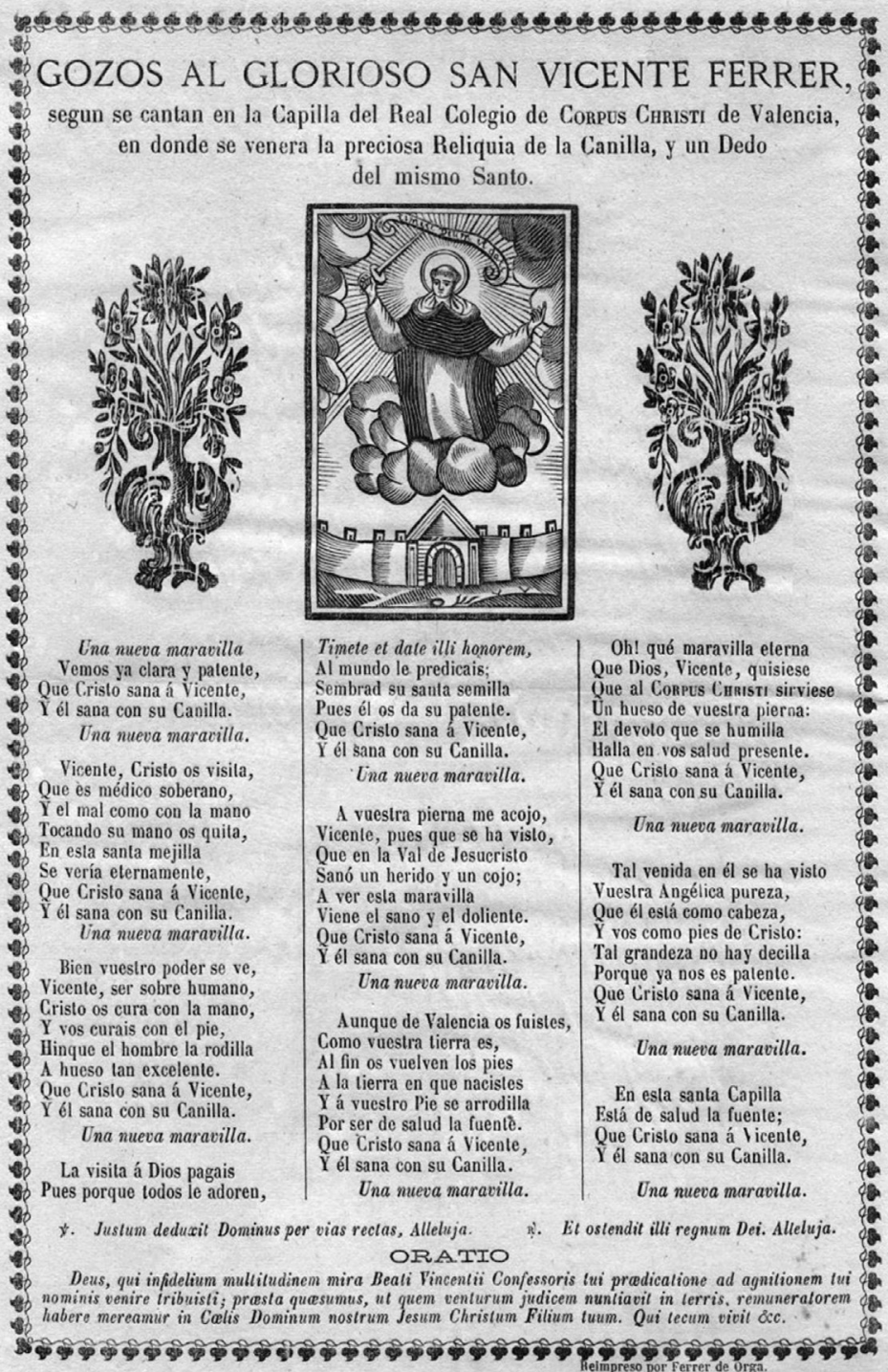

Fig. 2. [Juan de Ribera], Gozos al glorioso san Vicente Ferrer, según se cantan en la capilla del Real Colegio de Corpus Christi de Valencia..., [València], Ferrer de Orga, [1830 ca.]

REVISTA VALENCIANA DE FILOLOGIA / I I I (20I9) p. 287-322

JOAN CARLES GOMIS CORELL

Els goigs valencians de sant Vicent Ferrer: cant, lloança i lloança al sant / 306 


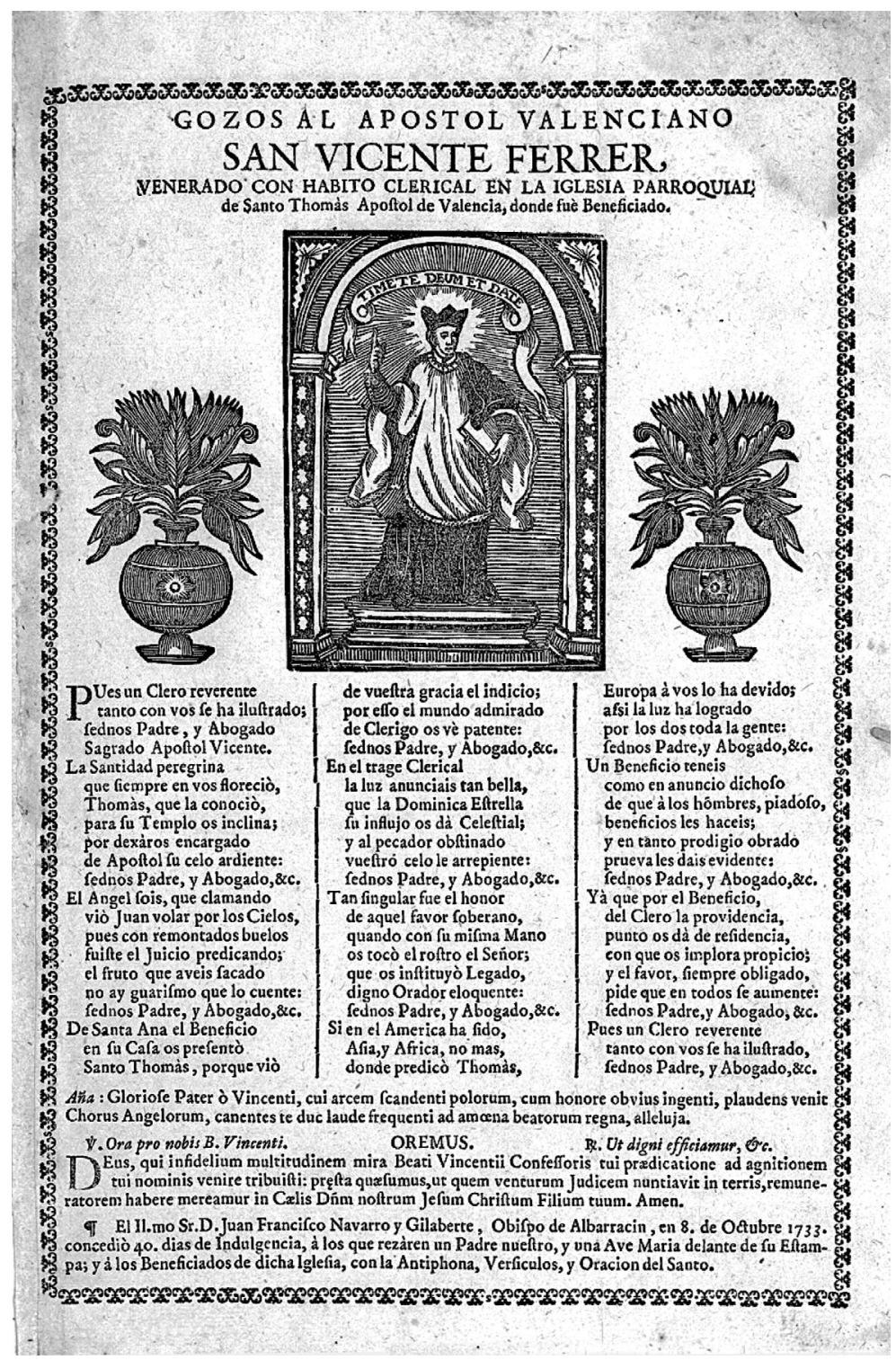

Fig. 3. [Anònim], Gozos al apóstol valenciano san Vicente Ferrer, venerado con hábito clerical en la iglesia parroquial de Santo Tomás..., s. 11. [València], s. i. [Benito Monfort], s. a. [1760 ca.], Biblioteca Valenciana, XVIII/F-420.

REVISTA VALENCIANA DE FILOLOGIA / I I I (20I9) p. 287-322 JOAN CARLES GOMIS CORELL

Els goigs valencians de sant Vicent Ferrer: cant, lloança i lloança al sant / 307 
També a final del 1600 o en 1601 degueren compondre's els Goigs del gloriós sant Vicent Ferrer, d'Agullent, els quals conten i canten -i cantant, lloen i celebren - el Miracle de la Pesta ocorregut el 4 de setembre del 1600 en aquell poble de la Vall d'Albaida. Són, per tant, propis i exclusius d'Agullent i també s'han estampat en diverses ocasions en fulls volanders. Emili Casanova (2015: 124-134) els ha estudiat i els ha transcrit amb deteniment, i fins i tot els ha recreat en la forma textual que possiblement tingueren en el moment de llur composició. No cal, per tant, dedicar-los ara i ací més temps ni espai.

Aquests dos nous goigs a sant Vicent, fets pràcticament encara no encetada la dissetena centúria, ja responen a uns plantejaments que definiran els goigs barrocs, distints dels de les llaors del segle xvi. Continuen incitant a la pietat i veneració del sant, però ara no per la contemplació piadosa de determinats valors i mèrits derivats de la seua fe, sinó per la seua potestat miraculosa de concedir favors, sobretot el guariment de malalties. Com ja hem dit en altres ocasions (Gomis Corell 2018: 132-138), els goigs barrocs assumiren el dictamen del Concili de Trento que legitimava recórrer a la intercessió i a l'auxili dels sants i de les imatges sagrades per atènyer beneficis de Déu, alhora que compendiaven en poques cobles els passatges més sensacionals - fins i tot sensacionalistes- de llurs vides, presentades com a models de comportament.

En el segle XVIII se'n compongueren dos més, de goigs, dedicats a sant Vicent Ferrer; ambdós, com fou habitual en aquell moment, en castellà. Uns, Gozos al apóstol valenciano san Vicente Ferrer, venerado con hábito clerical en la iglesia parroquial de Santo Thomás, apóstol, de Valencia, donde fué beatifcado, són propis del clero d'aquesta parròquia de la ciutat de València, el qual demana protecció i defensa al sant:

Pues un clero reverente tanto con vos se ha ilustrado, sednos padre y abogado, sagrado apòstol valenciano $[\ldots]$

REVISTA VALENCIANA DE FILOLOGIA / II I (20I9) p. 287-322 JOAN CARLES GOMIS CORELL

Els goigs valencians de sant Vicent Ferrer: cant, lloança i lloança al sant / 308 
No degueren sobrepassar l'àmbit d'aquesta parròquia. Se'n conserva una estampació en full volander eixida de la impremta de Benet Monfort, que podria datar-se al voltant del 1760 (fig. 3). ${ }^{16}$ Inclou aquesta estampació les indulgències que el bisbe d'Albarrasí Juan Francisco Navarro y Gilaberte concedí el 8 d'octubre del 1733 als qui resaren un parenostre i una avemaria davant l'estampa del sant. Tot i no poder assegurar que necessàriament l'estampa referida pel bisbe inclogués necessàriament aquests goigs, aquesta data potser acote el moment de la composició.

L'altra composició del segle XviII són els Loores —o gozos, perquè indistintament una o altra paraula n'encapçala el títol segons l'estampació- $a$ nuestro padre san Vicente Ferrer. Gran èxit i divulgació, tant editorial com de devoció, tingueren aquests nous goigs. Ho constata, primer de tot, la quantitat $\mathrm{i}$ diversitat d'estampacions en fulls volanders que se'n feren (fig. 4$),{ }^{17}$ en una conjuntura en la qual la religiositat barroca, qüestionada per les idees il-lustrades i jansenistes, tingué una bona aliada en la literatura de devoció, ara sí, clarament populista i, sense cap objecció, també popular en el sentit de destinada al consum dels sectors majoritaris de la societat $\mathrm{i}$, encara que amb algunes reserva —però no pertoca ara i ací entrar en aquest debat-, en el d'assimilació immediata, del missatge. Fon aleshores que s'inicià la definitiva transformació dels goigs en eina idònia per a exterioritzar la pietat dels fidels mitjançant el cant comunal en festes i processons, com ocorre actualment (Gomis Corell 2013). A la vegada, el full, amb el text i la imatge del corresponent personatge celestial —no mai amb la tonada per cantar-los-, es transformava en objecte de devoció en ell mateix. ${ }^{18}$

16 [Anònim], Gozos al apóstol valenciano san Vicente Ferrer, venerado con hábito clerical en la iglesia parroquial de Santo Thomás, apóstol, de Valencia, donde fué beatificado, s. 11. [València], s. i. [Benito Monfort], s. a. [1760 ca.], Biblioteca Valenciana, XVIII/F-420.

17 Quatre distintes d'entre la segona mitat del segle Xviı i les dues primeres dècades de la centúria següent en conserva la Biblioteca Històrica de la Universitat de València: BH. Var. 010(069), Var. 010(070), Var. 010(071), Var. 010(072).

18 Els fulls de goigs valencians no mai, llevat d'algun cas puntual i recent, duen la pauta musical amb la melodia; els catalans sí, però és pràctica que s'inicià a partir dels anys trenta del segle passat. Francesc Baldelló (1932: 9-10) es lamentava que fos «[...] tradicional prescindir de la tonada en l'edició de les fulles populars. [...] I encara és més de doldre que encara modernament no ens hàgim sabut esmenar d'aquest fer rutinari [...] És veritat que ja es publiquen algunes edicions acompanyades de la melodia corresponent. Però cal confessar que encara és un percentatge limitat i que manca molt per assolir l'ideal desitjat».

REVISTA VALENCIANA DE FILOLOGIA / I I I (20I9) p. 287-322

JOAN CARLES GOMIS CORELL

Els goigs valencians de sant Vicent Ferrer: cant, lloança i lloança al sant / 309 


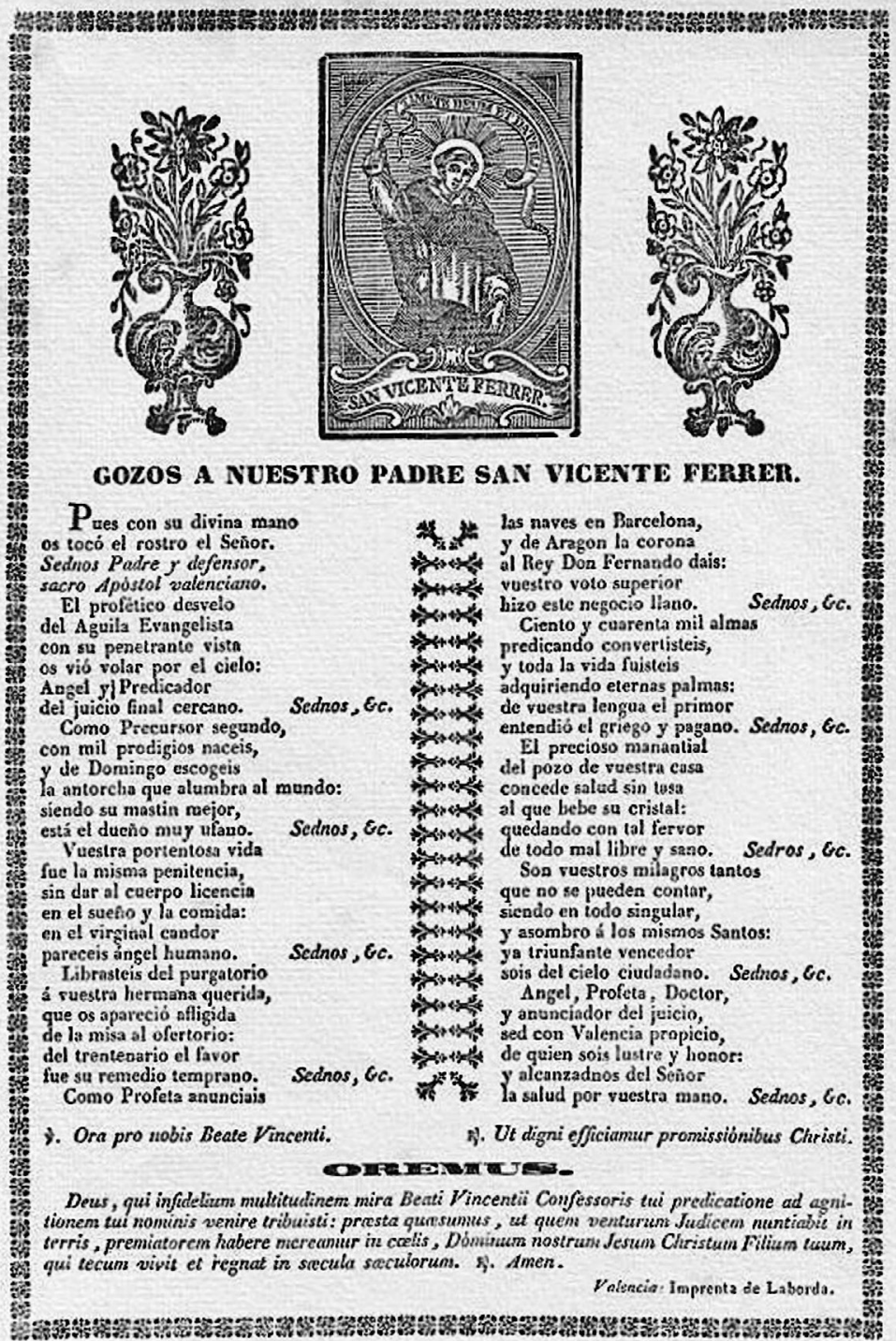

Fig. 4. [Anònim], Gozos a nuestro padre san Vicente Ferrer, s. 11.

[València], Imprenta de Laborda, s. a. [1760 ca.]

REVISTA VALENCIANA DE FILOLOGIA / I I I (20I9) p. 287-322

JOAN CARLES GOMIS CORELL

Els goigs valencians de sant Vicent Ferrer: cant, lloança i lloança al sant / 3 Io 
D’una banda, va ser aquest procés de generalització dels goigs —se'n dedicaren a totes les invocacions marianes i cristològiques, sants, santes, beats i misteris sagrats que hi havia a esglésies, capelles i ermites- i, de l'altra, de castellanització pràcticament total —aquesta segona circumstància fou distintiva, però, del País Valencià- d'un gènere nascut i conreat sempre en català, el que principalment conformà la tradició gogística valenciana com perviu en l'actualitat. ${ }^{19}$ Les Llaors del gloriós e benaventurat sent Vicent Ferrer, amb independència del grau d'expansió que hagueren pogut atényer pel país des de la primera publicació el 1548, deixaren de cantar-se i actualment són aquests gozos en castellà els que, llevat de casos puntuals, fan servir en la majoria dels pobles valencians on es venera el sant: Teulada i Alcoleja, Sant Vicent del Raspeig, Nules, Onda, Xert, Llucena, entre altres. ${ }^{20}$

\section{Uns goigs satiricopolítics a sant Vicent Ferrer del segle XIX}

En el segle XIX continuaren estampant-se en fulls volanders els goigs en castellà compostos en el segle XVIII. També se n'estamparen alguns en valencià dels que es compongueren en el segle Xvir — de la Mare de Déu del Puig, de la d'Aigües Vives, de la Consolació de Llutxent, els de sant Bernat d'Alzira, entre altres (Ribelles Comín, 1978: 90-93)—. Quant a sant Vicent Ferrer, el 1855, com era de rigor, se celebraren les festes del segle quart de la canonització. L'aleshores cronista de la ciutat de València, Vicent Boix (1855), va ser-ne

19 Aquesta castellanització fou bastant intensa ja en els anys centrals del segle XviII. A més de la gran quantitat d'estampacions de goigs que ho evidencien, n'és ben indicatiu que Ortí y Mayor (1750: 153) especifique que, d'entre tots els goigs i diverses oracions que fra Gaspar Bono cantava —a sant Vicent màrtir, sant Valer, sant Cristòfol, santa Agnés, santa Anna, etc.— només «[...] a san Vicente Ferrer le cantava, puesto de rodillas, sus gozos en lengua valenciana».

20 A Teulada aquests goigs en castellà han estat traduïts al valencià el 2008 per Jaume Buigues, i s'han publicat en un full que inclou la melodia amb la qual es canten; Buigues, Jaume (2008) Gojos a sant Vicent Ferrer, patró de la vila de Teulada, València, Imprenta de Sanchis.

REVISTA VALENCIANA DE FILOLOGIA / I I I (20I9) p. 287-322

JOAN CARLES GOMIS CORELL

Els goigs valencians de sant Vicent Ferrer: cant, lloança i lloança al sant / 3 I I 
l'autor del preceptiu llibre, en el qual recollí totes les poesies de la Corona poètica que es dedicà al sant. No cap composició de goigs.

Aquell mateix any, el número 9 del diari El Mole (14-IV-1855: [2]), fruit de l'entusiasme vicentí despertat per la celebració del centenar, publicava uns goigs satiricopolítics dedicats als sant, els quals li demanaven un miracle perquè milloràs la situació politicosocial del moment. Els transcrivim tot seguit: ${ }^{21}$

En el dia que els valencians dediquen a selebrar en festes públiques de músiques y tabalet y donsaina al patró de Valensia, al gloriós sen Visent Ferrer, El Mole, el més valensià del món, selebra també este dia; obsèquia al sant y dóna la preferència dabant de tot a les súpliques que li dirichix per a que fasa uns cuants milacres, en los siguients Gochos a sen Visent Ferrer.

Ya que teniu, gran siñor, els milacres en la mà, sigau nostre defensor, sacre aspòstol valensià.

Pare sen Visent Ferrer, sant molt docte y milagrós! feu que córrega el diner, que no hi à un chavo de a dos; tragau de l'estat més crític esta nasió desdichà, perquè el còlera polític a tots mos acabarà si, per llàstima y amor, no sou nostre defensor, sacre apòstol valensià.

21 La transcripció del text ha estat feta respectant el lèxic i les grafies originals; s'ha regularitzat l'ús de majúscules i minúscules, s'han separat les paraules, usat el guionet i l'apòstrof, accentuat i puntuat segons la norma actual.

REVISTA VALENCIANA DE FILOLOGIA / II I (20I9) p. 287-322

JOAN CARLES GOMIS CORELL

Els goigs valencians de sant Vicent Ferrer: cant, lloança i lloança al sant / 3 I 2 
Vinga la cosa com vinga, per polacos o santons, hi à en Madrid una exeringa que mos chupla hasta els sisons. Que el poble apenque y apenque, si un milacre no se fa, que la eixeringa mos trenque, res d'este món mos valdrà; feu-lo, pues, y així, sinyor, sigau nostre defensor, sacre apòstol valensià.

L'añ mil cuatre-sents y vint foreu diputat de corts, y entonses tan a sobint els diputats no eren borts. Hòmens fins per a Castella, com el Visent que la honrà, era un·atra chent aquella que alsaba neta la mà. Hui, entre tant d'agarraor, sigau nostre defensor, sacre apòstol valensià.

Carlistes y lliberals, d'eixos que busquen pa y mel, per a quedar tots iguals mos falta tirar la fel. Ya van ministres amunt, aball ministres van ya, y may ix del mateix punt la roda que rodant va. P.a fer-la nova, siñor, sigau nostre defensor, sacre apòstol valensià.

REVISTA VALENCIANA DE FILOLOGIA / I I I (20I9) p. 287-322 JOAN CARLES GOMIS CORELL

Els goigs valencians de sant Vicent Ferrer: cant, lloança i lloança al sant / 3 I 3 
Tocant altísims rechistres

feu un milacre en lo dit,

$\mathrm{p} \cdot \mathrm{a}$ que no tingam ministres

ni vacha un sisó a Madrit.

Dels partits y de ambisions

en asò la causa està;

lleveu-la en tres bendisions

y España felís serà

si, contra el tuno y traïdor,

sou el nostre defensor,

sacre apòstol valensià.

Quins pecats pogué cometre

esta gran nasió al revés,

que Déu no li vol permetre

ni gobern, ni pau ni res?

A trompis y a rebolcons

té d'anar sempre com va,

mudant de constitusions

com de ministres mudà

per a estar sempre pichor?

Sigau nostre defensor,

sacre apòstol valensià.

Feu-mos, sen Vicent Ferrer, sant gloriós y beneït, el milacre de desfer el mal que se fa en Madrit.

Que l'embroll no siga etern, y done-mos vostra mà

llibertat y bon gobern

com Déu als hòmens manà;

y entonses més y millor

sereu nostre defensor,

sacre apòstol valensià.

REVISTA VALENCIANA DE FILOLOGIA / I I I (20I9) p. 287-322

Els goigs valencians de sant Vicent Ferrer: cant, lloança i lloança al sant / 3 I 4 
Degueren tindre èxits aquests goigs. Es publicaren dues vegades més en el mateix diari: en el número 23 del 4 d'abril del 1864 i en el número 23 del 30 de gener del 1865 (Ribelles Comín 1978: 90).

\title{
7. Els goigs a sant Vicent Ferrer en el segle xx i principi del XxI
}

Encara en el segle xx es continuaren component goigs a sant Vicent Ferrer. Uns són els titulats $A$ sant Visent Ferrer, del prevere José Bau Burguet (1920: 40-42), l'entrada inicial dels quals diu:

\author{
Digam tots, chóvens y ansians, \\ plens de goig y de plaer: \\ viva sant Vicent Ferrer, \\ el patró d'els valencians! [...]
}

Són, juntament amb als goigs que dedicà $A$ la Verche dels Desamparats de Mataró (Bau Burguet 1926: 159-161), els únics que escrigué en valencià de tota la seua àmplia producció. Ni tan sols els dedicats A Nuestra Señora de los Desamparados, patrona de Valencia, els compongué en valencià (Bau Burguet 1926: 11-14). Per tant, no han de relacionar-se aquests goigs a sant Vicent amb l'impuls literari immediatament previ de la Renaixença. Foren producte, com tots els altres que compongué, de l'afecció pel gènere que Bau Burguet declara a l'inici del pròleg del primer volum del Librito de gozos. En aquest pretenia fer una revisió de les composicions del gènere que ja havia escrit i havia publicat en diversos llibrets de novenaris i revistes i que, en paraules seues, «[...] a mis amigos gustaban y a mi no [...]»; per tant, els reescrigué, «[...] presentándolos en este librito tan corregidos, que casi no parecen los mismos algunos de ellos» (Bau Burguet 1920: 9-10). No hi transcriu cap melodia, ni hi fa cap indicació de com cantar-los. Hagué de considerar que les mateixes melodies conegudes i usades pels fidels, simplement canviant-los la lletra, serien les més adients.

REVISTA VALENCIANA DE FILOLOGIA / I I I (20I9) p. 287-322 JOAN CARLES GOMIS CORELL

Els goigs valencians de sant Vicent Ferrer: cant, lloança i lloança al sant / 3 I 5 
De 1945 són els Goigs a sant Vicent Ferrer, d'Algímia d'Alfara, compostos per Jeroni Gómez, mestre d'escola vinculat a aquesta localitat, amb motiu de la restitució de la imatge del sant titular — havia sigut destruïda en la Guerra Civil espanyola del 1936-1939- de la parròquia, com en refereix la primera cobla: «[...] Algímia, en deler cordial, / davant vostra nova imatge, / vos rendix ver homenatge [...]». Van estar analitzats, transcrits i editats en estudi monogràfic (Gomis Corell 2001), al qual remetem. ${ }^{22}$ Es canten amb un dels tipus melòdics més propis de la tradició valenciana per a cantar goigs, el mateix que fan servir tant a Agullent, com a Teulada i Alcoleja [Seguí 1973: 31] (fig. 5).

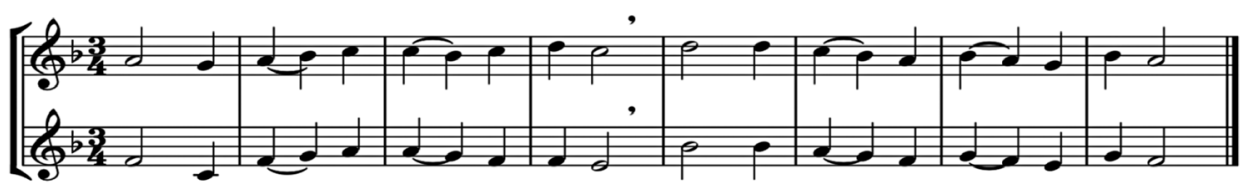

Fig. 5. Tipus melòdic, molt estés per tot el territori valencià, amb el qual es canten els goigs de sant Vicent Ferrer d'Algímia d'Alfara, Agullent, Teulada i Alcoleja.

De data posterior als d'Algímia d'Alfara semblen ser els Gojos de sant Vicent Ferrer de Borriol, estampats en full volander recent, en el qual el text segueix la normativa ortogràfica actual. Inclou també el full la melodia amb la qual es canten, de ritme ternari —emparentada amb la que a Sagunt usen per cantar els Gozos de Nuestra Señora del Buen Suceso (Gomis Corell: 2002, 260261)_, amb dues veus estrictament paral-leles en el moment de cantar els dos darrers versos de la cobla i el respòs. ${ }^{23}$

Finalment, trobem goigs actuals dedicats al sant dominicà a Sant Joan de Moró, compostos per José Bautista Bergés Vidal l’any 2007 amb un nivell de

22 A Rafelcofer hi ha uns goigs a sant Vicent amb només dues cobles relacionats amb els d'Algímia, per tal com la primera és igual que la segona dels d'Algímia d'Alfara; estan publicats en full volander: Festa de Sant Vicent Ferrer, Rafelcofer. Gojos al gloriós sant Vicent Ferrer, s. 11., s. i., 2000.

23 Borriol, Col-lecció particular: [Anònim], Gojos de sant Vicent Ferrer, s. ll. s. i., s. a.

REVISTA VALENCIANA DE FILOLOGIA / II I (20I9) p. 287-322

JOAN CARLES GOMIS CORELL

Els goigs valencians de sant Vicent Ferrer: cant, lloança i lloança al sant / 316 
llengua cult i completament normatiu. ${ }^{24}$ També a Llíria, amb motiu de la commemoració dels sis-cents aniversari del miracle que en aquella localitat obrà el sant, es compongueren i es publicaren el 2010 un goigs a sant Vicent, la llengua dels quals, més pròxima a la parla valenciana habitual que en la composició anterior, $\mathrm{fa}$ algunes concessions a formes no normatives. ${ }^{25}$

\section{Breu coda final}

El recorregut històric pels goigs valencians de sant Vicent Ferrer, amb independència d'altres consideracions — bé positives bé negatives-, mostra com aquell impuls poètic, musical i de devoció expressat en llengua vernacla que s'inicià en la segona mitat del segle $\mathrm{xv}$, i que florí excepcionalment a final d'aquella mateixa centúria i en la primera meitat de la següent, ha arribat sense interrupció fins al present, tot i que la composició més valuosa, tant literàriament com musical, les Llaors del gloriós e benaventurat sent Vicent Ferrer, hagen perdut llur vigència. Continuen component-se i cantant-se goigs, alguns tan antics i propis — pocs, és cert, però ben significatius, com ara els de la Mare de Déu del Roser o els de la del Puig-, que lliguen el present, conscientment i majoritàriament inconscient, a aquell inici. Els goigs canten sentiments i creences religioses, alhora que narren esdeveniments més o menys llunyans en el temps i més o menys ajustats a realitat, construeixen personatges —els divinitzen, però alhora també els humanitzen — i descriuen i limiten llocs on situen aquells personatges i ocorren aquells esdeveniments. Són producte de la història, però també de la geografia. Els goigs de sant Vicent fan present la ciutat de València per naixença i, per «apostòlic i profeta», ens fan recórrer diversos territoris d'una Europa immersa en el Cisma

24 Bergés Vidal, José Bautista, Goigs en honor a sant Vicent Ferrer, venerat a la sena ermita del paratge de la Font del Ros, en el terme municipal de Sant Joan de Moró, s. 11., s. i. 2007.

25 [Anònim], Gojos a sant Vicent. 600 anys d'un miracle, Llíria 1410-2010, Llíria, s. i., s. a. [2010]; [Anònim], Gojos a sant Vicent Ferrer, Llíria, Co[n]fraria Sant Vicent Ferrer., s. a. [2010].

REVISTA VALENCIANA DE FILOLOGIA / I I I (20I9) p. 287-322 JOAN CARLES GOMIS CORELL

Els goigs valencians de sant Vicent Ferrer: cant, lloança i lloança al sant / 3 I 7 
d'Occident, però també llocs del territori més immediat i propi —Agullent, Borriol, Llíria o Algímia d'Alfara- on sermonà, feu miracles o, si més no, s'aturà per descansar. Consegüentment, aquest goigs —els goigs en general一, sense pretendre afirmar que siguen metarelats que mitifiquen sant Vicent per a construir o, si més no, reforçar una identitat d'índole ètnica mitjançant un personatge històric de gran transcendència religiosa, ideològica i política, però fet domèstic, són expressió més que de creences religioses, de la consciència pròpia, acceptada o no.

REVISTA VALENCIANA DE FILOLOGIA / II I (20I9) p. 287-322 JOAN CARLES GOMIS CORELL

Els goigs valencians de sant Vicent Ferrer: cant, lloança i lloança al sant / 3 I 8 


\section{Bibliografia}

Almarche, F. (1917) Goigs valencians. Sigles XV al XIX, València, s. i.

Amades, J.; Colomines, J. (1946-1948) Imatgeria popular catalana. Els goigs, Barcelona, Orbis (2 vols.).

Anglés, H. (1958) La música de las Cantigas de Santa María del rey Alfono el Sabio, III, Barcelona, Diputación Provincial de Barcelona, Biblioteca Central.

AnTich, V. J. (1575) La vida y historia del apóstol predicador sant Vicente Ferrer, valenciano, de la orden de sancto Domingo..., València, Pedro Huete.

Baldelló, F. (1932) Cançoner religiós de Catalunya. Recull de cent melodies de goigs, Barcelona, Boileau Bernasconi.

Ballús i Casòliva, G.; Ezquerdo Esteban, A. (2013) «La primera edición conocida de gozos polifónicos a la manera de las hojas volantes (Barcelona, 1702)», Revista Catalana de Musicologia, VI, pp. 83-111.

Bau Burguet, J. (1920) Librito de gozos, tom i, València, M. Guillot Aguilar.

(1926) Librito de gozos, tom I, València, Tipografía Moderna.

Berjano Pellicer, C. (2015) «Cómo convertirse en músico profesional. Los jóvenes y el oficio de la música en el Siglo de Oro", Andalucía en la historia, juliol de 2015, pp. 80-83.

Bermudo, J. (1555) Declaración de instrumentos musicales, Osuna, Juan León.

Boix, V. (1855) Fiestas que en el siglo IV de la canonización de san Vicente Ferrer se celebraron en Valencia, València, Sociedad Económica de Amigos del País.

Briz, P. et al. (1877) Cansons de la terra. Cants populars catalans, vol. v, Barcelona, Àlvar Berdaguer; París, Maisonnueve \& C.

Calahorra, P. (1977) Historia de la música en Aragón (Siglos I-XVII), Saragossa, Librería General.

Carbajal, E. B. (2001) «La hagiografía en los pliegos sueltos españoles del siglo XVI», Via Spiritus, 10, pp. 81-111.

Carbonell, J. (2017) Elements d'història de la llengua, València, Publicacions de la Universitat de València.

Carreres Zacarés, S. (1926) Ensayo de una bibliografía de libros de fiestas celebradas en Valencia y su antiguo reino, Valencia, Hijo de F. Vives Mora.

Casanova, E. (2015) «Els Goigs de sant Vicent Ferrer d'Agullent del segle Xvir. Edició crítica», Llibre de Festes d'Agullent, pp. 124-134.

Cervera, J.: Las tres púrpuras de Alzira, Bernardo, María y Gracia. Vida y martirio de los tres santos hermanos, posesión, manutención y promoción del culto que han tenido [...], València, Jaime Bordázar, 1707.

Chabás, R. (ed.) (1904) Lahors de la Verge Maria, Jaume Roig, Barcelona, L’Avenç.

REVISTA VALENCIANA DE FILOLOGIA / I I I (20I9) p. 287-322

JOAN CARLES GOMIS CORELL

Els goigs valencians de sant Vicent Ferrer: cant, lloança i lloança al sant / 3 I9 
Combes, B. (1714), Feliz hallazgo del más rico y celestial tesoro, María Santíssima, aplaudida en su peregrina imagen [de] Nuestra Señora de Campanar..., València, Vicente Cabrera.

Comes, J. B. [Vicente Báguena Soler, transcr.] Cuatro gozos con polifonia, València, Instituto Valenciano de Musicología, Institución Alfonso el Magnánimo, Diputación Provincial de Valencia, 1955.

Esquerdo, J. (1599) Tratado copioso y verdadero de la determinación del gran monarcha Phelipe II para el samiento del III con la sereníssima Margarita de Austria, y entradas de Sus Magestades y grandes, València, s. n. [Juan Crisóstomo Garriz], junto al molino de Rovella.

Ferrando, A. (1987) «La literatura popularista al País Valencià durant la Decadència. El segle XVII", en Rafael Alemany (ed.), Estudis de literatura catalana al País Valencià, Alacant, Ayuntamiento de Benidorm / Universidad de Alicante, pp. 55-74.

Flos [Anònim] [Catalunya, mossén (ed.)] (1514) Flos sanctorum novament stampat, corregit $e$ ben examinat... afegides certes vides que fins ací no eren, València, Jorge Costilla.

Gallico, C. (1986 [1978]) Historia de la música. 4. La época del humanismo y del renacimiento, Madrid, Taurus.

Genovés y Olmos, Eduardo (1911) Catàlech descriptiu de les obres impreses en llengua valenciana, València, Manuel Pau.

Gómez, V. (1602), Relación de las famosas fiestas que hizo la ciudad de Valencia a la canonización del bienaventurado san Raymundo de Penyafort, en el convento de predicadores, Valencia, Juan Crisóstomo Garriz, a costa de Gaspar Mançano.

Gomis Corell, J. C. (1993), «Dues melodies tradicionals de gojos al Camp de Morvedre», Braçal. Revista d'Estudis del Camp de Morvedre, 7, pp. 37-53.

- (1996), "Els "Gozos al santísimo Cristo de la Sangre" i els "Gozos al ínclito y glorioso mártir san Sebastián” de Polinyà de Xúquer», Al-Gezira, 9, pp. 479-503.

- (1999) «Una estructura culta para un género tradicional: los gozos de Joan Baptista Comes. Su influencia en la tradición musical valenciana», en C. J. Sánchez Erquicia (ed.), Actas del IV Congreso de la Sociedad Ibérica de Etnomusicología. Granada, 9-12 julio 1998, [Pamplona], Sociedad Ibérica de Etnomusicología, pp. 171-195.

- (2001) Els Gojos a sant Vicent Ferrer, d'Algímia d'Alfara. Estudi, transcripció musical $i$ edició, Algímia d'Alfara, Ajuntament d'Algímia d'Alfara.

- (2002) «Los gozos marianos en la comarca del Campo de Morvedre. Estudio histórico y documental», Revista de Musicología, XXV (1), pp. 251-281.

- (2013) «Docere et delectare: poesia, música i imatge devocionals en defensa de la religiositat barroca contrareformista al darrer barroc valencià», eHumanista/IVITRA, 3, pp. 258-271.

- (2015) «Corroborar llegendes, invocar imatges, renovar la memoria i presentar models. El valor dels goigs en la religiositat valenciana durant la Contrareforma», Scripta. Revista Internacional de Literatura i Cultura Medieval i Moderna, 5, pp. 139-158.

REVISTA VALENCIANA DE FILOLOGIA / II I (20I9) p. 287-322 JOAN CARLES GOMIS CORELL

Els goigs valencians de sant Vicent Ferrer: cant, lloança i lloança al sant / 320 
— (2018) «Històries escrites, històries pintades. Els goigs en el Barroc valencià», Scripta. Revista Internacional de Literatura i Cultura Medieval i Moderna,11, pp. 121-158.

Gozos [Gerónimo de la Torre] (1702) Gozos de las virtudes y milagros del seráphico y gran patriarcha san Bruno, fundador de la Sagrada Orden de la Cartuxa. Tono nuevo y proprio a los sobredichos gozos compuesto por el maestro Gerónimo de la Torre; Fran. Gazán esculpit. Barcelona, s. i., Biblioteca de Catalunya, TOP: I Go A R.15134.

Lozano, J. (ed.) (2012) Coses evengudes en la ciutat y regne de València. Dietari (15851629), Pere Joan Porcar, València, Universitat de València.

Martínez de la Vega, J. (1620) Solenes i grandioses fiestas que la noble i leal Ciudad de Valencia a echo por la beatificación de su santo pastor i padre don Tomás de Villanueva, València, Felipe Mey

Ortí, M. A. (1656) Segundo centenario de los años de la canonización del valenciano apóstol san Vicente Ferrer, concluido el día de san Pedro y san Pablo, 29 de junio, del año 1655, València, Jerónimo Villagrassa.

Ortí y Mayor, J. V. (1731), Vida, virtudes, milagros y festivos cultos de santo Thomás de Villanueva, arzobispo de Valencia, de la orden de nuestro gran padre san Agustín, València, Juan González.

- (1750) Pasmosa vida, virtudes y milagros del venerable padre fra Gaspar de Bono, provincial de los mínimos de la provincia de Valencia, València, Josep Tomàs Lucas.

Peres, M. (1510) La vida de sant Vicent Ferrer, València, Joan Jofré.

Rebullosa, J. (1601) Relación de las grandes fiestas que en esta ciudad de Barcelona se han echo a la canonización de su hijo san Ramón de Peñafort, de la orden de Predicadores, Barcelona: Jaime Cendrat.

Recebimiento [Anònim] (1600) Recebimiento de la santíssima reliquia del glorioso sant Vicente Ferrer, que se tuxo a la venturosa ciudad de Valencia: con entera noticia de las muchas luminarias, fiestas, galas, invenciones... València, [s. i.], junto al molino de la Rovella.

Ribelles Comín, J. (1929) Bibliografía de la lengua valenciana... Tomo II (siglo XVI), Madrid, a expensas del Estado.

- (1978) Bibliografía de la lengua valenciana. Tomo IV (siglo XIX), Madrid, Servicio de Publicaciones del Ministerio de Educación y Ciencia

Ribera, Juan de (1594) Synodus diocesana Valentina, celebrata prae... València, Álvaro Franco.

Rubio, S. (1983) Historia de la música española. Desde el ars nova a 1600, Madrid, Alianza.

Seguí, S. (1973) Cancionero musical de la provincia de Alicante, Alacant, Diputación Provincial de Alicante.

- (1980) Cancionero musical de la provincia de Valencia, València: Institución Alfonso el Magnánimo, Diputación Provincial de Valencia.

- (1990) Cancionero musical de la provincia de Castellón, Segorbe, Caja Segorbe-Caja de Valencia-Fundación Caja Segorbe.

REVISTA VALENCIANA DE FILOLOGIA / I I I (20I9) p. 287-322

JOAN CARLES GOMIS CORELL

Els goigs valencians de sant Vicent Ferrer: cant, lloança i lloança al sant / $32 \mathrm{I}$ 
TÁrrega, F.- (1600) Relación de las fiestas que el arçobispo y Cabildo de Valencia hizieron en la translación de la reliquia del glorioso san Vicente Ferrer a este santo tempo..., València, Pedro Patricio Mey.

Tosca, T. (1727) Compendio mathemático, en que se contienen todas las materias más principales de las ciencias que tratan de la cantidad. Tomo II, Madrid, Antonio Marín [València, Antonio Bordázar, 1709].

Trellat [anònim] (1535) Trellat sumàriament fet de la bulla o confraria del Psaltiri o Roser,e cobles a lahor e glòria de la sacratíssima e entemerada Verge Maria del Roser, València, Nicolás Durán de Salvaniach.

- (1546) Trellat sumàriament fet de la bulla o confraria del Psaltiri o Roser, e cobles a lahor e glòria de la sacratíssima e intemerada Verge Maria del Roser, València, s. i.

Vidal y Micó, F. (1735) Historia de la portentosa vida y milagros del valenciano apóstol de Europa san Vicente Ferrer. Valencia, Estevan Dolz.

REVISTA VALENCIANA DE FILOLOGIA / III (20I9) p. 287-322

JOAN CARLES GOMIS CORELL

Els goigs valencians de sant Vicent Ferrer: cant, lloança i lloança al sant / 322 